\title{
Energy Use and GDP in Israel
}

\author{
Cosimo Magazzino ${ }^{1,2,3}$ \\ ${ }^{1}$ Department of Political Sciences, Roma Tre University, Italy \\ ${ }^{2}$ Italian Economic Association (SIE), Italy \\ ${ }^{3}$ Royal Economic Society (RES), UK \\ Correspondence: Cosimo Magazzino, Department of Political Sciences, Roma Tre University, Via G. Chiabrera \\ 199, 00145, Rome (RM), Italy. Tel: 39-33-1687-6907. E-mail: cosimo.magazzino@uniroma3.it.
}

Received: July 29, 2015

doi:10.5539/jsd.v8n9p89
Accepted: September 8, 2015 Online Published: November 23, 2015

URL: http://dx.doi.org/10.5539/jsd.v8n9p89

\begin{abstract}
The paper aims to study the relationship between energy use and GDP in the period 1971-2007 for Israel with a time-series approach. Stationarity and unit root tests reveal that both series are non-stationary, or $I(1)$. Moreover, since both series show the presence of a structural break, the Gregory and Hansen cointegration test has been conducted. The results evidence the presence of a long-run relationship. Causality tests reveal that the "conservation hypothesis" emerges, since the causality flow runs from aggregate income to energy use. The IRFs analysis evidences that a shock to the energy use affects GDP for one period, but dies out very quickly. While shocks to GDP create a smaller but significant response in the energy use, although it falls to zero in few periods. Finally, we calculate with an ECM that the total long-run multiplier is 0.95 . The energy use will increase to correct the disequilibrium, with $68 \%$ of the (remaining) deviation corrected in each subsequent time period. In addition, a one-unit increase in the GDP immediately produces a 0.18 unit increase in the energy use.
\end{abstract}

Keywords: energy use, GDP, time series, Israel

\section{Introduction}

The causal relation between energy consumption and economic growth has been a well-studied topic. Energy is one of essential factors for any country's economic development and therefore plays an important role in economic activities. Energy demand, supply and pricing impact on the socio-economic development, the living standards and the overall quality of life of the people (Iwayemi, 1998). On the other hand, higher level of economic development could induce more energy consumption.

Although multiple causality analyses have been conducted for several countries in the world, however, only Magazzino (2015) has analyzed the Israeli context.

For the state of Israel, located amidst a hostile neighborhood of oil supplying countries, the need for energy security is paramount. In addition, Israel's global obligation to reduce negative environmental impacts has become a major focus of public policy. In addition, the energy economy remains extremely self-sufficient. Electricity is entirely generated domestically, and there are no grid connections with any neighboring economies, aside from Gaza and the West Bank, where Israel has commitments to supply energy. Energy intensity, both on a per capita basis and relative to GDP, is fairly low in international comparison contributing factors are relatively small energy-intensive sectors, a reasonably favorable climate, high population density and middle-ranking GDP per capita. Renewable energy via solar-thermal panels for water heating has long been extensively exploited (Hemmings, 2011).

This paper examines the relationship between energy use and GDP in the case of Israel for the years 1971-2007, via time series methodologies. The results might help to define and implement the appropriate energy development policies in Israel (Magazzino, 2015).

Besides the Introduction, the rest of the paper is organized as follows. Section 2 describes the empirical literature on the relationship between energy use and aggregate income. Section 3 contains a description of the data the empirical results. Section 4 presents some concluding remarks. 


\section{Literature Survey}

The debate among economists regarding the relationship between energy consumption and economic growth has become increasingly intense in recent years. Interestingly, applied researchers paid very little attention to the relationship between energy and GDP in Israel. As a matter of fact, the Israeli case were considered only in panel data analyses.

As regards the Organization for Economic Co-operation and Development (OECD) countries, Chontanawat et al. (2006) tested for causality between energy and GDP using a dataset of 30 OECD and 78 non-OECD countries. Causality from aggregate energy consumption to GDP and GDP to energy consumption is found to be more prevalent in the developed OECD countries compared to the developing non-OECD countries. Lee et al. (2008) studied a set of 22 OECD countries using annual data covering the period 1960-2001, investigating the relationship between energy consumption and income using an aggregate production function and controlling for the capital stock. The panel causality test shows bi-directional causal linkages among energy consumption, the capital stock and economic growth. Apergis and Payne (2010) examined the relationship between renewable energy consumption and economic growth for a panel of twenty OECD countries over the period 1985-2005 within a multivariate framework. The heterogeneous panel cointegration test reveals a long-run equilibrium relationship between real GDP, renewable energy consumption, real gross fixed capital formation, and the labor force with the respective coefficients positive and statistically significant. The Granger-causality results indicate bidirectional causality between renewable energy consumption and economic growth in both the short- and long-run. Liddle (2012) examine changes in energy intensity trends for OECD countries over 1960-2009. Empirical findings suggest that, for several countries, energy intensity had a significant positive trend followed by a break and then a significant negative trend. Wong et al. (2013) explored the relationship among energy consumption, energy R\&D and real GDP in OECD countries over the period of 1980-2010. The results show that the role of energy R\&D should not be overlooked and fossil fuel R\&D is found to drive economic growth more than fossil fuel consumption.

As concerns Middle East and North African (MENA) countries, Al-mulali (2011) examined the impact of oil consumption on the economic growth of the MENA countries during the period 1980-2009. Cointegration results show that $\mathrm{CO}_{2}$ emission, and oil consumption has a long run relationship with economic growth. Moreover, there is also a bi-directional Granger causality between oil consumption, $\mathrm{CO}_{2}$ emission and economic growth in both the short run and the long run. Arouri et al. (2012), implemented bootstrap panel unit root tests and cointegration techniques to investigate the relationship between carbon dioxide emissions, energy consumption, and real GDP for 12 MENA countries over the period 1981-2005. The results show that in the long-run energy consumption has a positive significant impact on $\mathrm{CO}_{2}$ emissions. More interestingly, real GDP exhibits a quadratic relationship with $\mathrm{CO}_{2}$ emissions for the region as a whole. Farhani and Ben Rejeb (2012) investigated the relationship between energy consumption, GDP and $\mathrm{CO}_{2}$ emissions for 15 MENA countries covering the annual period 1973-2008. The finding reveals that there is a causal link neither between GDP and energy nor between $\mathrm{CO}_{2}$ emissions and energy in the short-run. However, in the long-run, there is a unidirectional causality running from GDP and $\mathrm{CO}_{2}$ emissions to energy consumption. Talbi (2012) analyzed energy intensity for a panel of six MENA countries, for the period 1980-2007. The results show that the energy intensity of GDP depends largely on the level of investment, the structure of economies and the rate of urbanization. Farhani et al. (2013) studied the Environmental Kuznets Curve (EKC) for 11 MENA countries over the period 1980-2009. Policy implications indicate that: more energy use, higher GDP and greater trade openness tend to cause more $\mathrm{CO}_{2}$ emissions. Omri (2013) examined the nexus between $\mathrm{CO}_{2}$ emissions, energy consumption and economic growth using simultaneous-equations models with panel data of 14 MENA countries over the period 1990-2011. The empirical results show that there exists a bidirectional causal relationship between energy consumption and economic growth.

\section{Data and Empirical Findings}

For the purpose of this paper, we derived the logarithmic transformations of the two variables. This study uses time-series data of real per capita GDP and per capita energy consumption for the 1971-2007 years in Israel. The data are derived from the Total Economy Database, and from the International Energy Agency (IEA) (Note 1). Per capita energy use $(E U)$ is expressed in terms of kg oil equivalent, while per capita GDP $(Y)$ in constant 1990 US\$. Moreover, the choice of the starting period was constrained by the availability of data on energy use.

Figure 1 depicts the series in the log-scale (left-hand panel) and in first differences (right-hand panel). Descriptive statistics are shown in Table 1. 

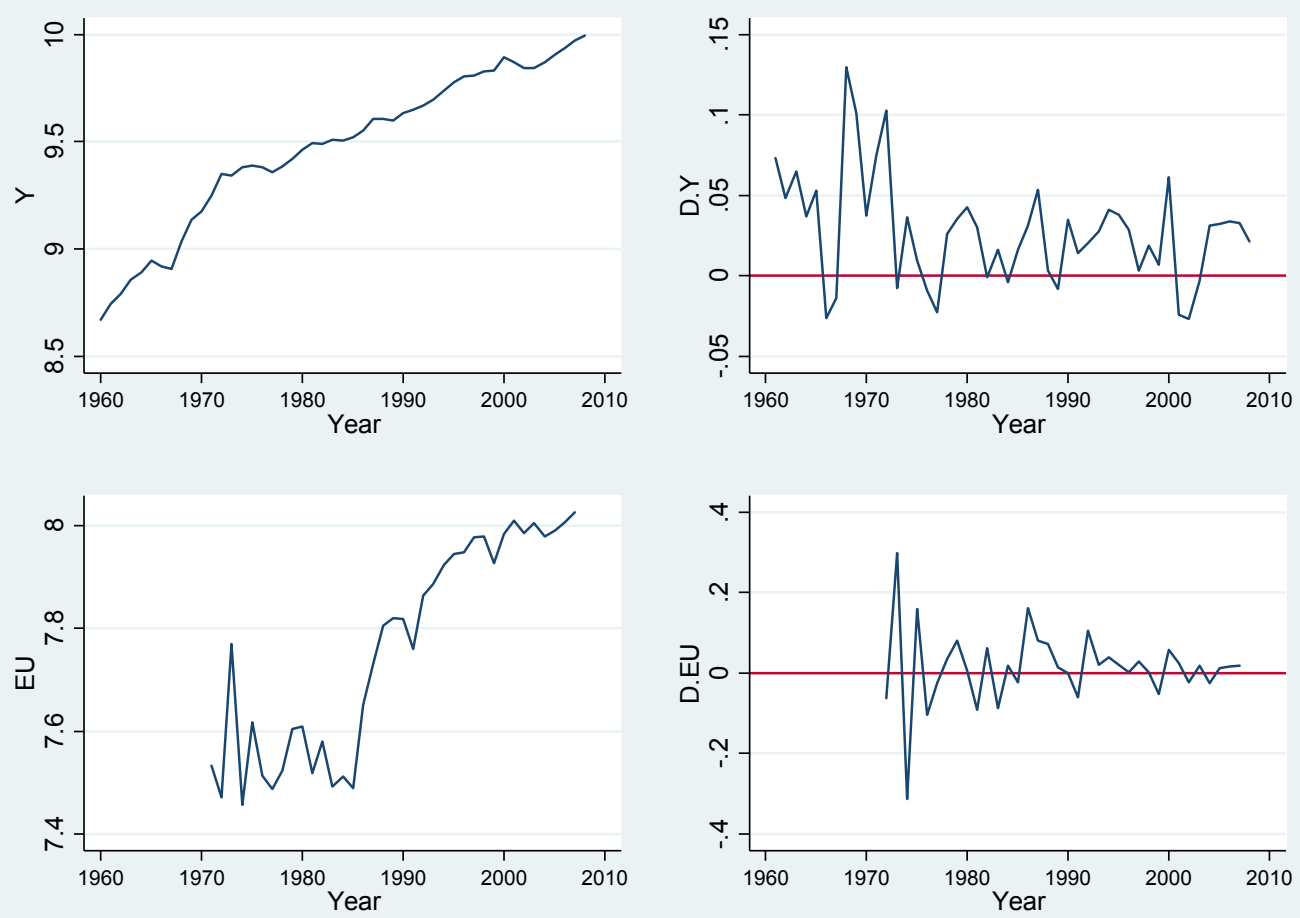

Figure 1. Real per capita GDP and energy use in Israel (1960-2008, log-scale)

Sources: TED and IEA data.

Table 1. Exploratory data analysis

\begin{tabular}{l|llllll}
\hline Variable & Mean & Median & Standard Deviation & Skewness & Kurtosis & IQR \\
\hline Y & 9.4743 & 9.5079 & 0.3631 & -0.5931 & 2.3614 & 0.4604 \\
EU & 7.7620 & 7.8046 & 0.2044 & -0.1694 & 1.4096 & 0.4428 \\
\hline
\end{tabular}

Sources: our calculations on TED and IEA data.

The correlation analysis reveals that the two series are strongly correlated, since the correlation coefficient $(r)$ is equal to 0.9181 , which is statistically significant at $1 \%$ level. In addition, these results are confirmed by cross correlations analysis, since increases in actual GDP are correlated with future increases in energy use, and increases in energy use are correlated with future GDP increases. 
Table 2. Results for unit roots and stationarity tests

\begin{tabular}{|c|c|c|c|c|c|}
\hline \multirow[t]{2}{*}{ Variable } & \multicolumn{5}{|c|}{ Unit root and stationarity tests } \\
\hline & Deterministic component & ADF & ERS & PP & KPSS \\
\hline $\mathrm{Y}$ & constant, trend & $\begin{array}{l}-2.359 \\
(-3.512)\end{array}$ & $\begin{array}{l}-1.304 \\
(-3.195)\end{array}$ & $\begin{array}{l}-2.500 \\
(-3.508)\end{array}$ & $\begin{array}{l}0.436^{* * *} \\
(0.146)\end{array}$ \\
\hline $\mathrm{EU}$ & constant, trend & $\begin{array}{l}-1.894 \\
(-3.560)\end{array}$ & $\begin{array}{l}-1.633 \\
(-3.293)\end{array}$ & $\begin{array}{l}-3.612 * * \\
(-3.556)\end{array}$ & $\begin{array}{l}0.180^{* *} \\
(0.146)\end{array}$ \\
\hline$\Delta \mathrm{Y}$ & constant & $\begin{array}{l}-4.606^{* * *} \\
(-2.941)\end{array}$ & $\begin{array}{l}-2.330 * * \\
(-2.253)\end{array}$ & $\begin{array}{l}-5.216^{* * *} \\
(-2.938)\end{array}$ & $\begin{array}{l}0.428^{*} \\
(0.463)\end{array}$ \\
\hline$\Delta \mathrm{EU}$ & constant & $\begin{array}{l}-5.434 * * * \\
(-2.975)\end{array}$ & $\begin{array}{l}-2.836^{* * *} \\
(-2.374)\end{array}$ & $\begin{array}{l}-11.089 * * * \\
(-2.972)\end{array}$ & $\begin{array}{l}0.071 \\
(0.463)\end{array}$ \\
\hline
\end{tabular}

Notes: The tests are performed on the log-levels of the variables. ADF, ERS, PP, and KPSS refers respectively to the Augmented Dickey-Fuller test, the Elliot, Rothenberg, and Stock point optimal test, the Phillips-Perron test, and the Kwiatkowski, Phillips, Schmidt, and Shin test. 5\% Critical Values in parentheses. When it is required, the lag length is chosen according to the SBIC. ${ }^{*} p<0.10 ; * * p<0.05 ; * * * p<0.01$.

In Table 2, the results of four unit root and stationarity tests are presented. Here, results indicate that the two series are non-stationary in their levels, but stationary in first differences. Thus, we can conclude that $Y$ and $E U$ variables are individually integrated of order 1 , or $I(1)$.

Table 3. Results for additive outlier unit root tests (single structural break)

\begin{tabular}{lllll}
\hline Variable & Optimal break point & $\mathbf{k}$ & t-stat & $\mathbf{5 \%}$ Critical Value \\
\hline Y & 1987 & 1 & -2.527 & -3.560 \\
EU & 1989 & 1 & $-4.624^{* * *}$ & -3.560 \\
$\Delta \mathrm{Y}$ & 1974 & 0 & $-6.108^{* * *}$ & -3.560 \\
$\Delta \mathrm{EU}$ & 1985 & 2 & -0.809 & -3.560
\end{tabular}

Notes: * significant at $10 \%$; ** significant at $5 \%$; *** significant at $1 \%$.

From Table 3 we note that the break detected by the Clemente, Montañés and Reyes (1998) test roughly corresponds to the First Intifada in the Eighties. Despite the structural break, we are unable to reject the null of unit root in these series; yet, if we perform the test at the first differences, our series become stationary: so, we can conclude again that GDP and energy consumption are I(1) processes.

Since structural breaks emerge in our series, we applied the Gregory and Hansen (1996) cointegration test with breaks. However, the tests clearly indicate the presence of a long-run relationship between aggregate income and energy use, with a break in constant and trend.

Table 4. Gregory and Hansen cointegration tests

\begin{tabular}{ccccc}
\hline Country & Constant & Constant and trend & Constant and slope & Constant, slope and trend \\
\hline Israel & $-5.09^{* *}(1965)$ & $-5.55^{* * *}(1981)$ & $-4.67(1989)$ & $-5.74 * *(1983)$ \\
\hline
\end{tabular}

Notes: * significant at $10 \%$;* significant at $5 \%$; ** significant at $1 \%$.

Since these two series are non-stationary, the spurious regression problem should be taken into account (Granger and Newbold, 1974). To this extent, we proceeded differencing the data. Granger (1969) causality tests following the Toda and Yamamoto (1995) approach requires the estimation of an augmented VAR $(k+d)$ model, where $k$ is the optimal lag length and $d$ is the order of the series' integration. All tests suggest inclusion of one lag in a VAR model, and so that $k=1$; hence, the final model to be estimated is $\operatorname{VAR}(2)$. To ensure that the VAR model is well 
specified and does not suffer from any normality or serial correlation problems, additional tests are carried out. Although the results are not reported to save space, diagnostic tests suggest the general absence of problems in the estimated $\operatorname{VAR}(2)$ model, with regard to normality and autocorrelation in the residuals, stability condition, and lag-exclusion. Figure A in the Appendix clarifies that the stability of coefficient estimates is supported, since the plots of both CUSUM and CUSUMSQ fall inside the critical bounds of 5\% significance. This indicates that the estimated parameters do not suffer from structural instability. However, both standard Granger causality tests as well as Toda and Yamamoto causality tests suggest that the "conservation hypothesis" holds, since we found unidirectional causality running from GDP to energy use.

Table 5. Results for causality tests

\begin{tabular}{ccccc}
\hline \multicolumn{5}{c}{ Granger test } \\
\hline Equation & Excluded & $\chi^{2}$-statistic & df & P-Value \\
$\Delta \mathrm{Y}$ & $\Delta \mathrm{EU}$ & 1.7644 & 1 & 0.184 \\
$\Delta \mathrm{EU}$ & $\Delta \mathrm{Y}$ & 13.4570 & 1 & $0.000^{* * *}$ \\
\hline \multicolumn{5}{c}{ Toda and Yamamoto test } \\
\hline $\mathrm{Y}$ & Excluded & $\chi^{2}$-statistic & df & P-Value \\
$\Delta \mathrm{EU}$ & $\Delta \mathrm{EU}$ & 2.9049 & 1 & 0.234 \\
\hline
\end{tabular}

Notes: * significant at $10 \% ; * *$ significant at $5 \% ; * * *$ significant at $1 \%$.

In the second column of Table 6 is reported the response of $Y$ to a shock in itself. We should remember that this series is stationary and, therefore, shocks are not persistent; their effects die out. Shocks to $E U$ are not persistent either. More interesting is how $Y$ responds to shocks in $E U$, and vice versa. The third column shows that a shock to $E U$ affects $Y$ for one period, but dies out very quickly. Finally, shocks to $Y$ create a smaller but significant response in $E U$, though once again it falls to zero in few periods.

Table 6. Results for impulse-response functions

\begin{tabular}{c|cccc}
\hline \multirow{2}{*}{ Step } & \multicolumn{3}{|c}{ Response: $\mathbf{Y}$} & \multicolumn{2}{c}{ Response: EU } \\
\cline { 2 - 5 } & \multicolumn{3}{|c}{ Impulse } & Impulse \\
\cline { 2 - 5 } & $\mathbf{Y}$ & $\mathbf{E U}$ & -0.3241 & $\mathbf{E U}$ \\
\hline 1 & -0.0576 & 0.1541 & 0.0151 & 0.0585 \\
3 & 0.0026 & -0.0072 & -0.0007 & -0.0028 \\
5 & -0.0001 & 0.0003 & -0.0000 & 0.0001 \\
10 & -0.0000 & -0.0000 & & -0.0000 \\
\hline
\end{tabular}

Finally, it is interesting the calculations of long and short-run multipliers. We then estimate the ECM. The results indicate the following equation:

$$
\Delta \mathrm{EU}_{\mathrm{t}}=0.9550+0.1766 \Delta \mathrm{Y}_{\mathrm{t}}-0.7206 \mathrm{EU}_{\mathrm{t}-1}+0.6814 \mathrm{Y}_{\mathrm{t}-1}+\varepsilon_{\mathrm{t}}
$$

However, we can rewrite the Equation (1) in error correction form as:

$$
\Delta \mathrm{EU}_{\mathrm{t}}=0.9550+0.1766 \Delta \mathrm{Y}_{\mathrm{t}}-0.7206\left(\mathrm{EU}_{\mathrm{t}-1}-0.9456 \mathrm{Y}_{\mathrm{t}-1}\right)+\varepsilon_{\mathrm{t}}
$$

Here, 0.95 is our calculation of the long-run multiplier. Given the fact that the coefficient of $E U_{t-1}$ is $-1<-0.72<$ 0 and statistically significant, we can conclude that our error correction approach is correct. Thus, according to these estimates, increases in $Y$ will cause deviations from the equilibrium state, causing $E U$ to be too low. $E U$ will then increase to correct this disequilibrium, with $68 \%$ of the (remaining) deviation corrected in each subsequent time period $\left(0.6814 \approx 0.7206^{*} 0.9456\right)$. Moreover, a one-unit increase in $Y$ immediately produces a 0.18 unit increase in $E U$. Increases in $Y$ also disrupt the long-run equilibrium relationship between these two variables, causing $E U$ to be too low. 
Furthermore, we can determine the standard error and confidence level of the total long-run effect of $Y$ on $E U$ through the Bewley (1987) transformation regression. We can see that our estimate of the long-run effect of $Y$ on $E U$ has a standard error of 0.0668 , and it is statistically significant at $1 \%$ level $(t=14.16)$.

Since the ECM is isomorphic to the Autoregressive Distributive Lag (ADL) model, we can rewrite our results in an $\mathrm{ADL}$ form as:

$$
\mathrm{EU}_{\mathrm{t}}=0.9550+0.2794 \mathrm{EU}_{\mathrm{t}-1}+0.1766 \mathrm{Y}_{\mathrm{t}}+0.5048 \mathrm{Y}_{\mathrm{t}-1}+\varepsilon_{\mathrm{t}}
$$

Therefore, our estimate of the contemporaneous effects of $Y$ on $E U$ is $=0.18$ units: the same as in the ECM. The short-run effect of $Y$ on $E U$ at $t+1$ can be calculated as $0.1766+0.5048=0.6814$, which is again equivalent to the 0.68 estimate in the ECM. So that, deviations from equilibrium are maintained at a rate of $68 \%$ per time period, which implies that deviations from equilibrium are corrected at a rate of $72 \%$ per time period $(0.2794-1)$. Finally, the total long-run effect (long-run multiplier) can be easily calculated as $(0.1766+0.5048) /(0.2794-1)=-0.9456$, which is equivalent to the ECM estimate.

\section{Conclusions and Policy Implications}

The aim of this paper is to analyze the energy use- aggregate income nexus in Israel, using time series econometric techniques. We studied the relationship between real per capita GDP and per capita energy use for Israel, using yearly data in the years 1971-2007. The time-series properties of the data were assessed using several unit root tests (ADF, ERS, PP, and KPSS). Furthermore, in order to evaluate the presence of eventual structural breaks, the CMR test has been conducted. Empirical findings indicate that both series are clearly non-stationary, or $I(1)$.

Moreover, cointegration analysis revealed that there is a long-run relationship between GDP and energy use. Further, causality tests showed that the "conservation hypothesis" holds for Israel, since a unidirectional causality flow that runs from aggregate income to energy use is found. Therefore, this implies that the policy of conserving energy consumption may be implemented with little or no adverse effect on economic growth in Israel, such as in a less energy-dependent economy.

Furthermore, the IRFs analyses show that the response of GDP to a shock in itself is not persistent, and this effect dies out; whilst, shocks to the energy use are not persistent either. In the bargain, a shock to $E U$ affects $Y$ for one period, but dies out very quickly. Finally, shocks to $Y$ create a smaller but significant response in $E U$, though once again it falls to zero in few periods.

Finally, we calculate with an ECM that the long-run multiplier is 0.95 . The energy use will increase to correct the disequilibrium, with $68 \%$ of the (remaining) deviation corrected in each subsequent time period. In addition, the short-run effect of GDP on energy consumption is 0.18 .

\section{Acknowledgements}

Comments from the anonymous referees and editor are gratefully acknowledged. However, the usual disclaimer applies.

\section{References}

Al-mulali, U. (2011). Oil consumption, CO2 emission and economic growth in MENA countries. Energy, 36, 6165-6171. http://dx.doi.org/10.1016/j.energy.2011.07.048

Apergis. N., \& Payne, J. E. (2010). Renewable energy consumption and economic growth: Evidence from a panel of OECD countries. Energy Policy, 38, 656-660. http://dx.doi.org/10.1016/j.enpol.2009.09.002

Arouri, M., Youssef, A. B., M'henni, H., \& Rault, C. (2012). Energy consumption, economic growth and $\mathrm{CO}_{2}$ emissions in Middle East and North African countries. Energy Policy, 45, 342-349. http://dx.doi.org/10.1016/j.enpol.2012.02.042

Bewley, T. F. (Ed.). (1987). Advances in Econometrics Fifth World Congress. Cambridge: Cambridge University Press.

Chontanawat, J., Hunt, L.C., \& Pierse, R. (2006). Causality between Energy Consumption and GDP: Evidence from 30 OECD and 78 Non-OECD Countries. Surrey Energy Economics Discussion paper Series, 113, June.

Clemente, J., Montañés, A., \& Reyes, M. (1998). Testing for a unit root in variables with a double change in the mean. Economics Letters, 59, 175-182. http://dx.doi.org/10.1016/S0165-1765(98)00052-4

Dickey, D. A., \& Fuller, W. A. (1979). Distribution of the estimators for autoregressive time series with a unit 
root. Journal of the American Statistical Association, 74, 427-431.

Elliott, G., Rothenberg, T. J., \& Stock, J. H. (1996). Efficient tests for an autoregressive unit root. Econometrica, 64, 813-836. http://dx.doi.org/10.2307/2171846

Engle, R. F., \& Granger, C. W. J. (1987). Co-Integration and Error Correction: Representation, Estimation, and Testing. Econometrica, 55(2), 251-276. http://dx.doi.org/10.2307/1913236

Farhani, S., \& Ben Rejeb, J. (2006). Energy Consumption, Economic Growth and $\mathrm{CO}_{2}$ Emissions: Evidence from Panel Data for MENA Region. International Journal of Energy Economics and Policy, 2(2), 71-81.

Farhani, S., Shahbaz, M., \& Arouri, M. (2013). Panel analysis of $\mathrm{CO}_{2}$ emissions, GDP, energy consumption, trade openness and urbanization for MENA countries, MPRA Paper, 49258, August.

Granger, C. W. J. (1969). Investigating causal relations by econometric models and cross-spectral methods. Econometrica, 37, 424-438. http://dx.doi.org/10.2307/1912791

Granger, C. W. J., \& Newbold, P. (1974). Spurious Regressions in Econometrics. Journal of Econometrics, 2, 111-120. http://dx.doi.org/10.1016/0304-4076(74)90034-7

Gregory, A. W., \& Hansen, B. E. (1996). Residual-Based Tests for Cointegration in Models with Regime Shifts. Journal of Econometrics, 70(1), 99-126. http://dx.doi.org/10.1016/0304-4076(69)41685-7

Hemmings, P. (2011). Addressing Challenges in the Energy Sector in Israel. OECD Economics Department Working Papers, 914.

Iwayemi, A. (1998). Energy sector development in Africa. African Development Report.

Kwiatkowski, D., Phillips, P. C. B., Schmidt, P., \& Shin, Y. (1992). Testing the null hypothesis of stationarity against the alternative of a unit root: How sure are we that economic time series have a unit root? Journal of Econometrics, 54, 159-178. http://dx.doi.org/10.1016/0304-4076(92)90104-Y

Lee, C. C., Chang, C. P., \& Chen, P. F. (2008). Energy-income causality in OECD countries revisited: The key role of capital stock. Energy Economics, 30, 2359-2373. http://dx.doi.org/10.1016/j.eneco.2008.01.005

Liddle, B. (2012). Breaks and trends in OECD countries' energy-GDP ratios. Energy Policy, 45, $502-509$. http://dx.doi.org/10.1016/j.enpol.2012.02.061

Magazzino, C. (2012). On the Relationship between Disaggregated Energy Production and GDP in Italy. Energy \& Environment, 23(8), 1191-1207. http://dx.doi.org/10.1260/0958-305X.23.8.1191

Magazzino, C. (2014a). Electricity Demand, GDP and Employment: Evidence from Italy. Frontiers in Energy, 8(1), 31-40. http://dx.doi.org/10.1007/s11708-014-0296-8

Magazzino, C. (2014b). Energy Consumption and GDP in Italy. Environment, Development and Sustainability, 17(1), 137-153. http://dx.doi.org/10.1007/s10668-014-9543-8

Magazzino, C. (2014c). The relationship between $\mathrm{CO}_{2}$ emissions, energy consumption and economic growth in Italy. International Journal of Sustainable Energy, forthcoming. http://dx.doi.org/10.1080/14786451.2014.953160

Magazzino, C. (2015). Economic growth, $\mathrm{CO}_{2}$ emissions and energy use in Israel. International Journal of Sustainable Development \& World Ecology, 22(1), 89-97.

Magazzino, C., \& Giolli, L. (2014). A Time Series Analysis of the Aggregate Income-Energy Consumption Nexus: the Case of Italy, Journal of Energy and Development, 39(1-2), 219-227.

Omri, A. (2013). $\mathrm{CO}_{2}$ emissions, energy consumption and economic growth nexus in MENA countries: Evidence from simultaneous equations models. Energy Economics, 40, 657-664. http://dx.doi.org/10.1016/j.eneco.2013.09.003

Talbi, B. (2012). Energy Intensity and Economic Growth in the MENA Region: Analysis of Panel Heterogeneous non Stationary. British Journal of Economics, Finance and Management Sciences, 6(2), 93-107.

Toda, H. Y., \& Yamamoto, T. (1995). Statistical inference in vector autoregressions with possibly integrated processes. Journal of Econometrics, 66(1-2), 225-250. http://dx.doi.org/10.1016/0304-4076(94)01616-8

Wong, S. L., Chang, Y., \& Chia, W. M. (2013). Energy consumption, energy R\&D and real GDP in OECD countries with and without oil reserves. Energy Economics, 40, 51-60. http://dx.doi.org/10.1016/j.eneco.2013.05.024 


\section{Notes}

Note 1. See, for more details: http://www.ggdc.net/databases/ted.htm and http://www.iea.org/.

\section{Appendix}

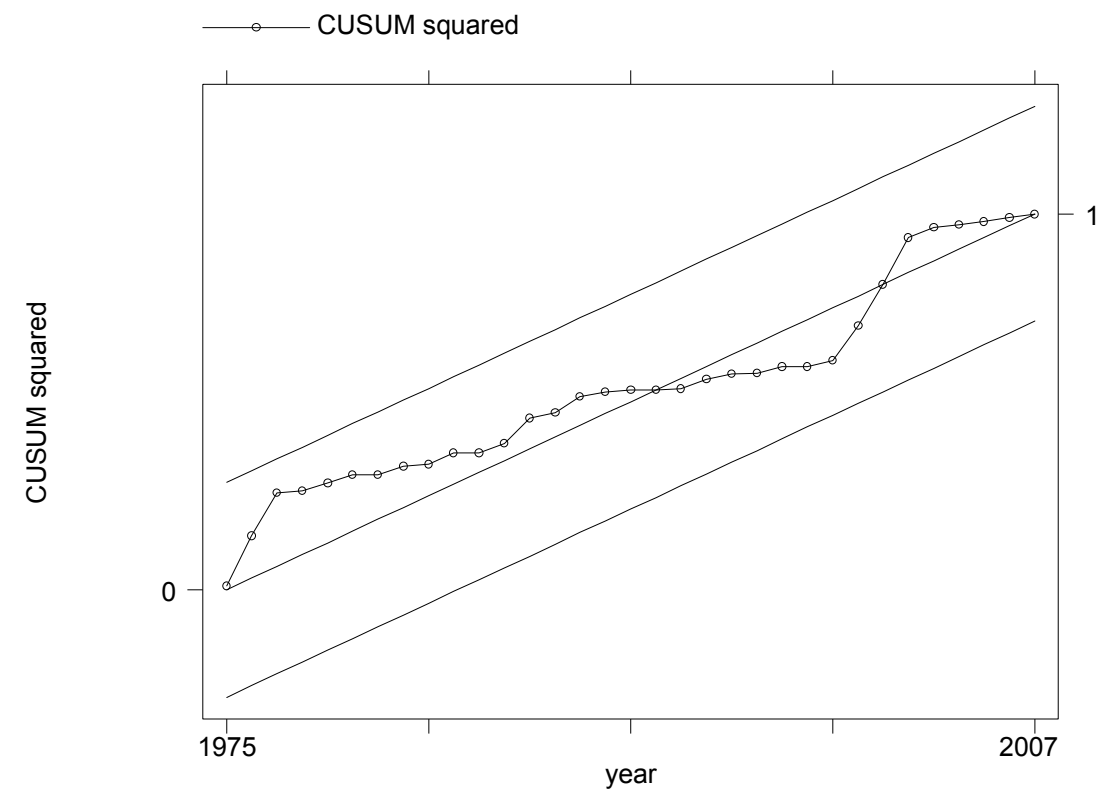

Figure A. Cumulative sums (CUSUM) of the recursive residuals

\section{Copyrights}

Copyright for this article is retained by the author(s), with first publication rights granted to the journal.

This is an open-access article distributed under the terms and conditions of the Creative Commons Attribution license (http://creativecommons.org/licenses/by/3.0/). 